\title{
A Review of Geoepidemiological Differences of Multiple Sclerosis in Iran and Other Middle East Countries
}

\author{
Zahra Tolou-Ghamari ${ }^{1, *}$ \\ ${ }^{1}$ Isfahan Neurosciences Research Centre, Isfahan University of Medical Sciences, Isfahan, IR Iran \\ ${ }^{*}$ Corresponding author: Zahra Tolou-Ghamari, Isfahan Neurosciences Research Centre, Isfahan University of Medical Sciences, Isfahan, IR Iran. Tel: +98-3136291050, E-mail: to- \\ loeghamari@pharm.mui.ac.ir
}

Received: July 13, 2014; Revised: September 1, 2014; Accepted: November 12, 2014

\begin{abstract}
Context: Review of epidemiological studies of different geographical regions show a wide variation in the prevalence of multiple sclerosis (MS) worldwide. This study compares related geoepidemiological differences in prevalence of MS in the Middle East.

Evidence Acquisition: Key words relevant to "prevalence of multiple sclerosis" were searched for with countries in the Middle East. Results: A prevalence of 31-55 per 100,000 individuals has been reported for Persian Gulf countries. The reported prevalence per Kuwait $(n=85.05)$ and United Arab Emirate $(n=54.4)$ seems to be high. The reported prevalence for Turkey and Jordan were 51 and 20 , correspondingly. Within Iran, the highest and lowest prevalence seem to belong to Isfahan $(n=93.06)$ and Golestan $(n=18.0)$, respectively. Immunomodulating drugs such as Interferon-beta as a first-line therapy; and cyclophosphamide, methotrexate, mitoxantrone, and azathioprine have been considered as second-line therapies.

Conclusions: The high prevalence of MS in the Middle East might be pointed toward the adverse effects of low vitamin D, individual daily life, smoking, Epstein-Barr virus infection, hereditary affects, and a history of depression.
\end{abstract}

Keywords:Middle East; Prevalence; Multiple Sclerosis

\section{Context}

Geoepidemiological studies of autoimmune illnesses such as Multiple Sclerosis (MS) may represent the influence of these infirmities across different areas and racial inhabitants. The epidemiology of MS has been altered in current decades in Iran and other Middle East regions to include the majority of Western Asia and Egypt but excluding the Caucasia (1-3). Prevalence studies offer applicable epidemiological information for a balanced approach to scheduling health care demand. Differences in genes, environment, and their interaction could be attributed to irregularly link to the prevalence of MS (46). According to previous publications associated with reported prevalences (n per 100,000) for three regions is recognized as follows:1) high-risk area $n>30 ; 2$ ) intermediate-risk area $\mathrm{n}=5-25$; and 3) low-risk area $\mathrm{n}<5$ (7). However, up to now, MS origin, prevalence, and geographical allocation are not blatant. The reported period of prevalence in Isfahan/Iran showed a remarkable rise in the prevalence of MS (8-16). Studies in Arab countries have also demonstrated that MS prevalence is on the rise. The pattern of disease in Qatar seems to be different from other Middle East countries from its milder clinical and aggressive radiologic disease presentations $(2,12)$. Therefore, a review related to a comparison of the epidemiology of MS in Iran and other countries in the Middle East is of interest and was investigated.

\section{Evidence Acquisition}

\subsection{Survey Method}

Population-based studies related to the prevalence of MS in Iran and other countries located in the Middle East were used. The Directory of Open Access Journals (DOAJ), Google Scholar, Information Science and Technology Abstracts (LISTA, EBSCO publishing), Web of Science, United States National Library of Medicine (PubMed, NLM), and National Institutes of Health with keywords relevant to the "prevalence of multiple sclerosis" were searched. A manual investigation of the reference records from principal editorial and pertinent analysis was also performed.

\subsection{Addition and Omission Norms}

The subsequent criterion were used to choose documents for inclusion in this review as follows: 1 ) data related to different cities in Iran; 2) data of prevalence related to the countries in the Middle East such as: Cyprus, Egypt, Iraq, Jordan, Kuwait, Lebanon, Oman, Palestine, Qatar, Saudi Arabia, Syria, Turkey, United Arab Emirates, and Yemen; and 3) articles that were found in a single center or did not engage a system of hospitals allocated to well-distinct general residents were disqualified. Figure 
1 demonstrates a summation of outcomes recognized in this assessment.

\subsection{Drawing out the Information and Appraising Study Eminence}

The records drawn-out were based on the studies to date i.e. June 2014. The total number of articles found related to search terms and the selected articles (for each country) between years $x-y$ were selected. The subsequent in- formation was extracted into Table 1 and included study place, reported prevalence, and the number of references. The data that were incorporated are in line with the period and population studied. Each study was appraised based on the category of study design, explanation of population, and the adequacy of the case descriptions. Finally, the reported prevalence of MS in Iran and other Middle East countries includes the total number of references found for each country in addition to the date of published (Table 1).

\begin{tabular}{|c|c|c|c|}
\hline Middle East, Reported Prevalence & Year & $\mathbf{n} / \mathbf{1 0 0 , 0 0 0}$ & Total No. of References \\
\hline Iran & & & A total of 103 articles; 13 were selected from 2013-2003 \\
\hline Tehran & 2010 & 51.9 & \\
\hline Qom & 2013 & 50.4 & \\
\hline All Iranian & 2013 & $5.3-70.4$ & \\
\hline Isfahan & 2010 & 93.06 & \\
\hline Cyprus & & & A total of 7 articles; 2 were selected from 1997-1991 \\
\hline $\begin{array}{l}\text { The overall MS in four areas } \\
\text { studied in Greek-speaking Cyprus }\end{array}$ & 1997 & 42 & \\
\hline Village, Liopetri & 1991 & 240 & \\
\hline Egypt & & & A total of 5 articles; 2 were selected from 2013 \\
\hline Al Quseir & 2013 & $\begin{array}{c}4.6 \% \text { (out of } \\
1531 \text { subjects) }\end{array}$ & \\
\hline Jordan & 1995 & 20 & A total of 13 articles; 3 were selected from 2013-1995 \\
\hline \multirow[t]{3}{*}{ Kuwait } & 2013 & 85.05 & A total of 14 articles; 5 were selected from 2013-1986 \\
\hline & 2000 & 14.77 & \\
\hline & 1993 & 6.68 & \\
\hline Qatar & 2010 & 64.57 & A total of 3 articles; 2 were selected from 2013 \\
\hline Saudi Arabia & & & A total of 7 articles; 5 were selected from 2013-1988 \\
\hline $\begin{array}{l}\text { A report regarding to the Persian } \\
\text { Gulf Region exists that confirm }\end{array}$ & 2013 & $31-55$ & \\
\hline The reported hospital & 1998 & 25 & \\
\hline Turkey & & & A total of 62 articles; 2 were selected from $2011-1960$ \\
\hline Kandira & 2011 & 31 & \\
\hline Geyve & & 41 & \\
\hline Erbaa & & 53 & \\
\hline Total & & 51 & \\
\hline \multicolumn{4}{|l|}{ United Arab Emirates } \\
\hline $\begin{array}{l}\text { according to the reported article } \\
\text { related to years } 2000-2007\end{array}$ & 2011 & 54.77 & A total of 2 articles; 1 was selected from 2011 \\
\hline Syria & & & $\begin{array}{l}\text { A total of } 2 \text { articles; } 2 \text { were selected from 2013-2009. Data not avail- } \\
\text { able }\end{array}$ \\
\hline Iraq & & & $\begin{array}{l}\text { A total of } 11 \text { articles; } 6 \text { were selected from 2013-1958. Data not avail- } \\
\text { able }\end{array}$ \\
\hline Yemen, Palestine & & & Not found. Data not available \\
\hline Lebanon & & & $\begin{array}{l}\text { A total of } 9 \text { articles; } 1 \text { was selected from } 2008 \text {. Data not available; } \\
\text { however, the estimated number ranged from } 1200-1700 \text { patients }\end{array}$ \\
\hline Oman & & & $\begin{array}{l}\text { A total of } 3 \text { articles; } 2 \text { were selected from 2009-2005. Data not } \\
\text { Available; however, from a total of } 30 \text { patients in } 2005 \text { estimated } 4 \text {. }\end{array}$ \\
\hline
\end{tabular}




\section{Results}

\subsection{Prevalence of Multiple Sclerosis in Iran}

Figure 1 shows the reported prevalence (8) expressed as $n$ per 100,000 for different regions of Iran that can be ranked from the highest to lowest as follows: Isfahan $(n=93.06)$, Charmahal and Bakhtiari $(n=92.7)$, Fars $(n=$ 77.3), Tehran ( $\mathrm{n}=74.3)$, Markazi $(\mathrm{n}=73.8)$, Hamadan $(\mathrm{n}=$ 62.6), Qom ( $n=50.4)$, Azerbaijan $(n=45.5)$, Kermanshah $(\mathrm{n}=43.7)$, Gilan $(\mathrm{n}=35.9)$, Zanjan $(\mathrm{n}=33.27)$, and Goles$\tan (\mathrm{n}=18.0)(8)$. In another study performed on 901 patients with MS in Isfahan, Iran showed that the mean age of patients was 34.6 years with an age range of 8-87 years (15). An additional study in the same region related to 3,522 patients showed that 2,716 were female and 806 were male and confirmed a prevalence figure of 73.3 and an incidence of 9.1 per 100,000 (11). A recent review of592 patients with MS in Qom, Iran described the mean age of disease onset was $34.25 \pm 9.01$, in which $11.2 \%$ had a positive family history and $80.1 \%$ demonstrated the relapsingremitting (RR) type (16). In a study in southeastern Iran with 206 patients with MS indicated an age range between16-50 years and a prevalence of 13.96 per 100,000. A total of $65.8 \%$ had the RR type of the disease (17). In capital city of Iran, Tehran, a study of 8,146 patients showed that $72.3 \%$ of patients were female and $27.7 \%$ were male with a mean age range for disease onset of 27.24 years With the RR type present in $84.9 \%$ of patients. The prevalence was reported as 51.9 per 100,000 (18).

\subsection{Prevalence of Multiple Sclerosis in Other Mid- dle East countries}

There is a considerable burden from MS in the Middle East as its prevalence emerges to have augmented distinctly in recent decades with a faster rate of increase in female versus male patients (Table 1). Figure 2 shows that Turkey, Syria, Iraq, Kuwait, Bahrain, Qatar, United Arab Emirates, and Oman are the most bordering Middle East countries bordering Iran.

The prevalence data related to Iraq, Lebanon, Syria, Yemen, Bahrain, and Palestine were not available. For Persian Gulf countries, a moderate-to-high prevalence with an increase in incidences in recent years has been reported $(2,3)$. Figure 3 indicates the study prevalence of MS as related to two communities in Cyprus such as the Turkish-speaking north and the Greek-speaking south have shown the prevalence of MS in Turkish Cypriot men was significantly higher than in Turkish Cypriot women. It was also significantly higher than among Greek Cypriot men. In the Greek-speaking metropolitan area of Nicosia, the prevalence of MS was 51 per 100,000 individuals. The overall MS prevalence in the four areas studied in Greekspeaking Cyprus, including three previously studied, was 42 per 100,000. There was a reported prevalence of 240 per 100,000 individuals for the village named Liopetri in
$1991(9,19)$. In Egypt, a study showed that the frequency of prevalence of studied neurological disorders could be ranked as follows: dementia, migraine, stroke, epilepsy, Parkinson's disease, cerebral palsy, spinal cord disorders, dystonia, trigeminal neuralgia, chorea, athetosis, and multiple sclerosis. The reported prevalence in this paper for MS was 13.74 per 100,000 individuals (20). Reported data regarding Turkey confirms a prevalence rate of 61 , 41, and 53 per 100,000 individuals for Kandira, Geyve, and Erbaa with a total of 51 per 100,000 individuals (21). In another report published in the journal of Neuroepidemiology in 2006, the prevalence of MS in Maltep (a district of Turkey) was accounted as 101.4 per 100,000 individuals (22). Benamer et al. in 2009 reported that in Kuwait, the incidence of MS was 2.08 per 100,000 individuals and prevalence varied from 4 to 42 per 100,000 individuals (7). Alroughani et al. in 2013 reported a prevalence of 85.1 per 100,000 individuals in Kuwait with an incidence of $6.88 \%(23,24)$.

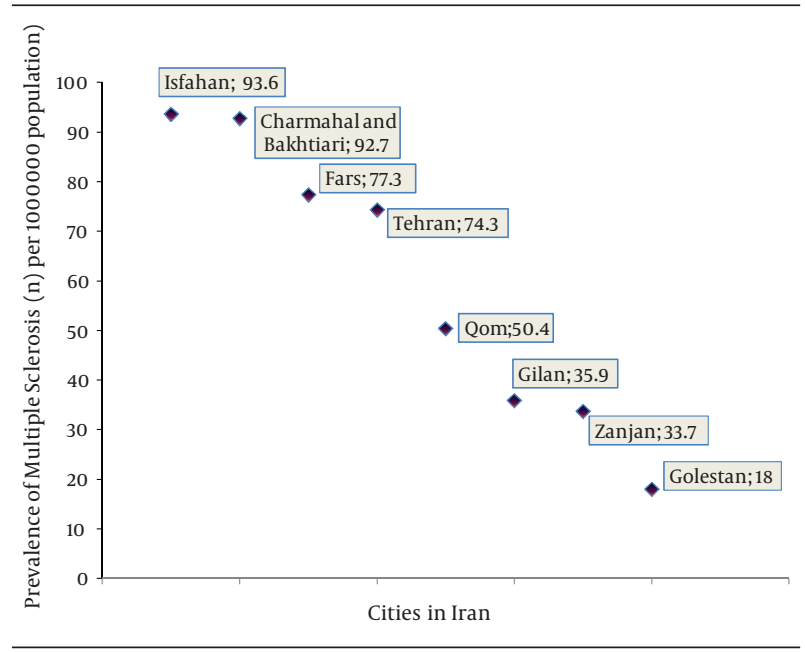

Figure 1. Prevalence of MS in Different Cities of Iran Ranked From Highest to Lowest (8)

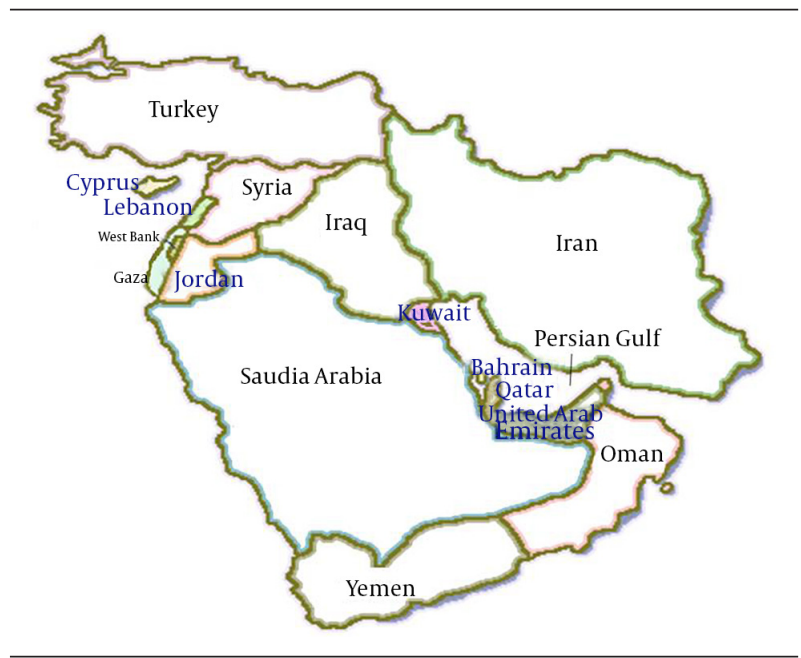

Figure 2. Iran and Other Middle East countries 


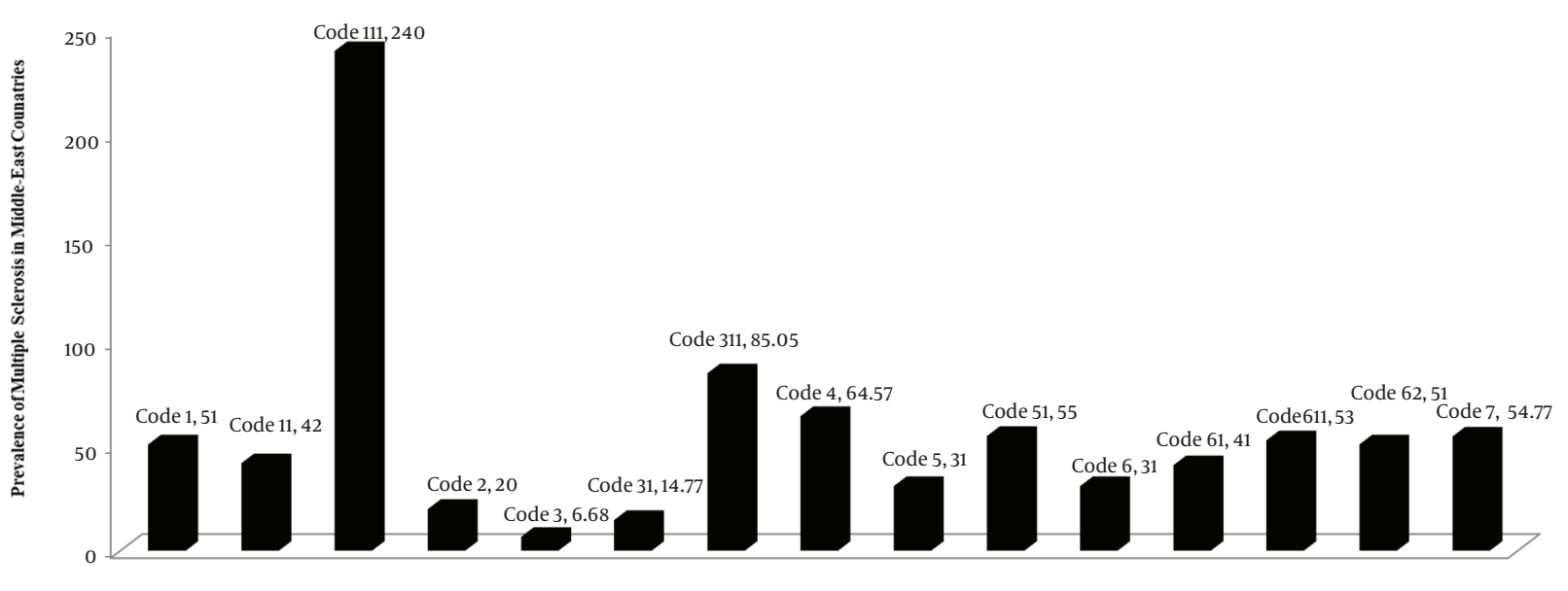

Codes that Represent The Middle-East Countries

Figure 3. Prevalence of MS in Other Middle East countries (1-24)

Abbreviations: Code 1: Greek-speaking metropolitan area of Nicosia (1997); Code 11: Four area Greek Speaking Cyprus (1997); Code 111:Cyprus;Village Lioperti (1991); Code 2: Jordan (1997); Code 3: Kuwait (1993); Code 31: Kuwait (2000); Code 311: Kuwait (2013); Code 4: Qatar (2013); Code 5: Saudi Arabia (2013): Code 51: Saudi Arabia (2013); Code 6: Turkey; Kandira (1960); Code 61: Turkey; Geyve (2011); Code 611: Turkey; Erbaa (2011); Code 62: Turkey; total (2011); and Code 7: United Arab Emirates (2011). Iraq, Yemen, Palestine, and Lebanon, are unknown.

\section{Conclusions}

The search results showed that the epidemiology of MS is quickly changing all over of the world and in the Middle East. It seems that there is a tendency in means of increasing with a doubling in incidences within the female population in the Middle East. In Iran, the highest $(n=93.6)$ and lowest population $(n=18)$ of MS was reported for Isfahan and Golestan, respectively (8-11, 15-18). Recent publications confirm that Iran has a moderate to high MS prevalence rate, with a recent sharp increase in this rate (25). Figure 3 shows that other Middle East countries such as the village Lioperti in Cyprus have a prevalence of 240 per 100,000 individuals and Kuwait have a prevalence rate of 85.05 per 100,000 individuals, which seems to show that these areas are high-risk areas. The data related to Kuwait seems to be interesting with a rise in the prevalence from 6.68 to 14.77 to 85.05 reported in years 1991, 2000, and 2013, correspondingly. However, the data related to Iraq, Yemen, Palestine, and Lebanon was not available but it seems that the lowest value related for the prevalence of MS might be related to that of Jordan, which has reported in 1997 a prevalence rate of 20 per 100,000 individuals. Medical explanations point toward many factors such as long-term changes regarding the corpus callosum area or plasma pro-inflammatory proteins such as the novel biomarker Pentrax in 3 levels. The presence of higher levels of depression, the frequency of immunological disease, polymorphisms in the receptors of vitamin D and cytochrome P27B1, the prevalence of infection from the Epstein-Barr virus, the existence of a higher correlation between latitude and the serum vitamin D levels are among the recommended areas to consider for future research in high prevalence areas such as Iran (26-29). According to a recent publication by Iranian scientists, autoimmune family history, MS family history, and personal allergy history are risk factors for MS susceptibility (30). Finally, new treatment strategies are available in Iran due to in biotechnological development. Increased specificity for new drugs in MS might indicate comparable superior value. In patients with PPMS, SP-MS, or inflammatory RR-MS, cyclophosphamide or mycophenolate might be used in treatment. For those patients who are unable to tolerate conventional therapies, azathioprine could be used. Beta interferons, Avonex, Cinovex, Recigen, Ziferon, and Rebif appear to slow the progress of multiple sclerosis and reduce the severity of attacks with further studies related to pharmacokinetics makes more convenient.

\section{Acknowledgements}

Author would like to express special thanks to the Isfahan University of Medical Sciences, Isfahan, Iran.

\section{Funding/Support}

Isfahan University of Medical Sciences, Isfahan, Iran supported this study.

\section{References}

1. Shapira Y, Agmon-Levin N, Shoenfeld Y. Defining and analyz ing geoepidemiology and human autoimmunity. J Autoimmun. 2010;34(3):[168-77.

2. Al Tahan AM, Alsharoqi I, Bohlega SA, Dahdaleh M, Daif A, Deleu D, et al. Characteristics of multiple sclerosis in the Middle 
East with special reference to the applicability of international guidelines to the region. Int J Neurosci. 2014;124(9):635-41.

3. Wikipedia . Middle East.. Available from: http://en.wikipedia.org/ wiki/Middle_East.

4. Kingwell E, Marriott JJ, Jette N, Pringsheim T, Makhani N, Morrow SA. Incidence and prevalence of multiple sclerosis in Europe: a systematic review. BMC Neurol. 2013;13:128.

5. Koch-Henriksen N, Sorensen PS. The changing demographic pattern of multiple sclerosis epidemiology. Lancet Neurol. 2010;9(5):520-32.

6. Tullman MJ. Overview of the epidemiology, diagnosis, and disease progression associated with multiple sclerosis. Am J Manag Care. 2013;19(2 Suppl):S15-20.

7. Benamer HT, Ahmed ES, Al-Din AS, Grosset DG. Frequency and clinical patterns of multiple sclerosis in Arab countries: a systematic review. J Neurol Sci. 2009;278(1-2):1-4.

8. Etemadifar M, Sajjadi S, Nasr Z, Firoozeei TS, Abtahi SH, Akbari M, et al. Epidemiology of multiple sclerosis in Iran: a systematic review. Eur Neurol. 2013;70(5-6):356-63.

9. Etemadifar M, Abtahi SH. Multiple sclerosis in Isfahan, Iran: Past, Present and Future. Int J Prev Med. 2012;3(5):301-2.

10. Etemadifar M, Janghorbani M, Shaygannejad V, Ashtari F. Prevalence of multiple sclerosis in Isfahan, Iran. Neuroepidemiology. 2006;27(1):39-44.

11. Etemadifar M, Maghzi AH. Sharp increase in the incidence and prevalence of multiple sclerosis in Isfahan, Iran. Mult Scler. 2011;17(8):1022-7.

12. Akhtar N, Elsetouhy A, Deleu D, Kamran S, AlHail H, Elalamy O. Newly diagnosed multiple sclerosis in state of Qatar. Clin Neurol Neurosurg. 2013;115(8):1333-7.

13. Poser CM, Paty DW, Scheinberg L, McDonald WI, Davis FA, Ebers GC, et al. New diagnostic criteria for multiple sclerosis: guidelines for research protocols. Ann Neurol.1983;13(3):227-31.

14. McDonald WI, Compston A, Edan G, Goodkin D, Hartung HP, Lublin FD. Recommended diagnostic criteria for multiple sclerosis: guidelines from the International Panel on the diagnosis of multiple sclerosis. Ann Neurol. 2001;50(1):121-7.

15. Tolou-Ghamari Z, Shaygannejad V, Ashtari F. Preliminary study related the incidence of methylprednisolone pulse therapy in patients visited multiple sclerosis clinic located at the isfahan kashani hospital. Int JPrev Med. 2013;4(Suppl 2):S274-8.

16. Rezaali S, Khalilnezhad A, Naser Moghadasi A, Chaibakhsh S, Sahraian MA. Epidemiology of multiple sclerosis in Qom: Demographic study in Iran. Iran J Neurol. 2013;12(4):136-43.

17. Moghtaderi A, Rakhshanizadeh F, Shahraki-Ibrahimi S. Inci- dence and prevalence of multiple sclerosis in southeastern Iran. Clin Neurol Neurosurg. 2013;115(3):304-8.

18. Sahraian MA, Khorramnia S, Ebrahim MM, Moinfar Z, Lotf J, Pakdaman H. Multiple sclerosis in Iran: a demographic study of 8,000 patients and changes over time. Eur Neurol. 2010;64(6):331-6.

19. Middleton LT, Dean G. Multiple sclerosis in Cyprus. J Neurologic Sci.;103(1):29-36.

20. Tallawy HN, Farghaly WM, Rageh TA, Shehata GA, Badry R, Metwally NA, et al. Door-to-door survey of major neurological disorders (project) in Al Quseir City, Red Sea Governorate, Egypt. Neuropsychiatr Dis Treat. 2013;9:767-71.

21. Boru UT, Tasdemir M, Guler N, Ayik ED, Kumas A, Yildirim S, et al. Prevalence of multiple sclerosis: door-to-door survey in three rural areas of coastal Black Sea regions of Turkey. Neuroepidemiology. 2011;37(3-4):231-5.

22. Turk Boru U, Alp R, Sur H, Gul L. Prevalence of multiple sclerosis door-to-door survey in Maltepe, Istanbul, Turkey. Neuroepidemiology. 2006;27(1):17-21.

23. Alroughani R, Ahmed SF, Behbahani R, Khan R, Thussu A, Alexander $\mathrm{KJ}$, et al. Increasing prevalence and incidence rates of multiple sclerosis in Kuwait. Mult Scler. 2014;20(5):543-7.

24. Dean G, Aksoy H, Akalin T, Middleton L, Kyriallis K. Multiple sclerosis in the Turkish-and Greek-speaking communities of Cyprus. A United Nations (UNHCR) Bicommunal Project. J Neurol Sci. 1997;145(2):163-8.

25. Izadi S, Nikseresht A, Sharifian M, Sahraian MA, Hamidian Jahromi A, Aghighi M, et al. Significant increase in the prevalence of multiple sclerosis in iran in 2011. Iran J Med Sci. 2014;39(2):152-3.

26. Zarei M, Basiri N, Jamnejad A, Eskandari MH. Prevalence of Escherichia coli O157:H7, Listeria monocytogenes and Salmonella spp. in Beef, Buffalo and Lamb Using Multiplex PCR. Jundishapur JMicrobiol. 2013;6(8).

27. Saharian MA, Shakaouri Rad A. , Motamedi M, et al... Magnetic resonance imaging abnormalities in multiple sclerosis: A review. Iran J Radiol.;4(4):231-9.

28. Shaygannejad V, Tolou-Ghamari Z. What is the Real Fate of Vitamin D in Multiple Sclerosis? Int J Prev Med. 2013;4(Suppl 2):S159-64.

29. Shaygannejad V, Dehnavi SR, Ashtari F, Karimi S. Study of type a and B behavior patterns in patients with multiple sclerosis in an Iranian population. Int J Prev Med. 2013;4(Suppl 2):S279-83.

30. Mansouri B, Asadollahi S, Heidari K, Fakhri M. Risk factors for increased multiple sclerosis susceptibility in the Iranian population. J Clin Neurosci. 2014. 